\title{
IFRS and Solvency II: Global Exposure and Interaction - The Work of the IAIS
}

\author{
Michel Flamée \\ CBFA, Rue du Congrès 12-14, B-1000 Brussels, Belgium. \\ E-mail: michel.flamee@cbfa.be
}

This paper sets out key principles on financial reporting by insurance companies. As a starting point, International Association of Insurance Supervisors supports the objective of having a substantial consistency between amounts disclosed to the public in financial reports and amounts reported to regulators for prudential purposes. In this context, the paper goes on to analyse a number of fundamental elements for the valuation of technical provision and explains the main differences identified so far between the accounting and regulatory approaches. The paper highlights several critical issues for further consideration, such as the need and the ways to ensure a consistent application of accounting standards. The Geneva Papers (2008) 33, 54-59. doi:10.1057/palgrave.gpp. 2510158

Keywords: financial and prudential reporting; IFRS for insurance liabilities; settlement and exit value; fair value; consistent application of IFRS; solvency II

\section{Introduction}

The International Association of Insurance Supervisors (IAIS) is an international organisation comprising insurance supervisors from over 180 jurisdictions in 130 countries, supervising insurers with approximately 97 per cent of the world insurance markets. One of its main objectives is to promote the development of well-regulated insurance markets. As this requires high-quality financial reporting, the IAIS has a strong interest in the development of high quality international financial reporting standards.

The IAIS takes particular interest in those projects of the International Accounting Standards Board (IASB) that will most influence the overall accounting model for regulated insurance enterprises in the interest of providing a meaningful, economically sound portrayal of these enterprises to the external markets.

The main current focus for the IAIS is Phase II of the IASB's Insurance Contracts Project, ${ }^{1}$ which will result in an international financial reporting standard for the valuation of insurance liabilities for general-purpose financial reporting, and is of crucial interest to the insurance industry and to insurance supervisors.

\section{Key IAIS Principles on Financial Reporting}

The IAIS believes that it would be most preferable if the methodologies for calculating items in public, financial reports are able to be used for, or are substantially consistent

\footnotetext{
${ }^{1}$ Referred to henceforth as "Phase II".
} 
with, the methodologies used for regulatory reporting purposes, with as few changes as possible to satisfy prudential reporting requirements. It is largely with this objective in mind that the IAIS is so actively monitoring developments at the IASB and providing input to the Board.

Although it is clearly preferable for the insurance contracts measurement model for prudential reporting to be consistent with that used for general-purpose financial reporting, this may not be possible or appropriate in all cases. However, the IAIS believes that it is essential that differences between prudential reporting requirements and general-purpose public reporting are reconcilable and that these differences are publicly explained. Otherwise, there is a risk that public confusion will call into question the credibility of both reporting regimes.

\section{Coordination of IAIS Work on Phase II and Solvency}

In view of the significance to the insurance industry and to insurance supervisors of the work of the IASB on insurance contracts, 2 years ago the IAIS established a new working party - the IAIS Insurance Contracts Subcommittee - specifically to coordinate the IAIS's position and provide input to the IASB with regard to its project on insurance contracts and other key, related projects.

The work of this subcommittee is closely coordinated with the IAIS's work on solvency assessment. At the same time as the IASB has been heavily engaged in Phase II, the IAIS has also been working on an ambitious project to define an international framework for solvency assessment. In February 2007, the IAIS published a paper, The IAIS common structure for the assessment of insurer solvency. ${ }^{2}$ This paper followed on from two papers released in 2005 A new framework for insurance supervision, ${ }^{3}$ followed by Towards a common structure and common standards for the assessment of insurer solvency: Cornerstones for the formulation of regulatory financial requirements. ${ }^{4}$ Many of the issues and challenges that face the IASB in Phase II are also identified and encompassed within this work.

The IAIS works in close cooperation with the International Actuarial Association (IAA) in its work on solvency assessment. With regard to the valuation of insurance liabilities, the IAIS asked the IAA for formal input to assist its work in this area. This has resulted in an exposure draft by the IAA of a paper, Measurement of liabilities for insurance contracts: current estimates and risk margins, ${ }^{5}$ which was released for consultation in February 2007. Work by IAA members on this paper has been ongoing in parallel with the recent IAIS work on insurance liabilities, and IAA members have participated closely in the IAIS work streams on both Phase II and solvency assessment. The IASB has also taken interest in this IAA project.

The European Commission is represented in both of the IAIS work streams mentioned above. In addition, many jurisdictions represented in the IAIS subcom-

\footnotetext{
2 IAIS (2007).

3 IAIS (2005a).

4 IAIS (2005b).

${ }^{5}$ IAA (2007).
} 
mittees working on Phase II and Solvency are also closely involved with the Solvency II project. IAIS work in these areas is hence progressing in close parallel with developments on Solvency II, and we have no cause to believe at this stage that there are significant differences in the philosophies underlying the respective projects or in compatibility of the expected outcomes.

\section{Basis for Work on Phase II}

As noted above, the IAIS has an overriding principle that "it would be most preferable if the methodologies for calculating items in public, financial reports are able to be used for, or are substantially consistent with, the methodologies used for regulatory reporting purposes, with as few changes as possible to satisfy prudential reporting requirements". In view of this the IAIS work on Phase II has been to study the possibility of using an International Financial Reporting Standards (IFRS)-compatible model as a basis for prudential supervision, taking into account the likely outcome of the IASB's Phase II project. More precisely, the mandate of the Insurance Contracts Subcommittee asks the question, "What methodologies for determining insurance liabilities, consistent with the likely outcomes of the ongoing IASB work, could be acceptable for prudential supervision?"

In its work to provide input to the IASB, the IAIS has assumed that the more likely outcome of Phase II will be a prospective asset/liability model with time value of money adjustments and risk margins (assumptions that remain valid). The themes addressed by the IAIS in its comments explore, on the basis of these assumptions, the likely characteristics of a compatible, sufficiently robust, general-purpose and regulatory reporting measurement model for insurance contracts, and what characteristics should not be in such a model.

\section{First and Second "Liabilities Papers"}

As a result of its work, the IAIS has now provided two comment papers to the IASB as input into the Phase II project. The First Liabilities Paper ${ }^{6}$ was issued in May 2005 and was followed a year later with a Second Liabilities Paper. ${ }^{7}$

The Second Liabilities Paper sets out a number of principles, or key observations, on measurement themes common to both general-purpose financial reporting and regulatory reporting that the IASB is addressing in Phase II.

The principles identified include various features of insurance liability measurement, risk margins and aspects of life insurance accounting. In addition to the overriding principle, quoted above, other key principles include the following observations:

- The future cash flows relating to full settlement with the claimant/beneficiary should be the basis for measuring insurance liabilities and this value is expected to

\footnotetext{
${ }^{6}$ Full title: Issues arising as a result of the IASB's Insurance Contracts Project - Phase II: Initial IAIS Observation; IAIS (2005c).

${ }^{7}$ Full title: Issues arising as a result of the IASB's Insurance Contracts Project-Phase II: Second Set of IAIS Observations; IAIS (2006)
} 
correspond to the transfer value of the liability. In this approach, insurance contracts should be measured as the sum of:

- The unbiased estimate of future cash flows reflecting the time value of money: current estimate (CE).

- An adjustment to reflect risk: a risk margin (whose calculation methodologies are explored by the IAA in cooperation with IAIS).

- No additional margin such as profit margin.

- An approach that uses observable inputs from deep and liquid markets to the fullest extent possible is appropriate in insurance liability valuation.

- Similar obligations with similar risk profiles should result in similar liabilities.

- Probabilities that reflect likely policyholder behaviour are needed to achieve meaningful results.

- Including adjustments for credit standing in the measurement of insurance liabilities would be misleading for users of general-purpose financial statements.

(Both Liabilities Papers are publicly available on the IAIS website at www.iaisweb.org.) A number of the key principles and observations in the paper are in full agreement with the preliminary Board decisions on Phase II. There are other principles where the IAIS position is in agreement with the preliminary conclusions of the Board, but with further elaboration. For example, the IASB advocates the idea of an "exit" model for the valuation of insurance liabilities. This model allows the concept that profits could arise at the inception of a contract (although the IAIS would not expect this to be a common occurrence). The IAIS supports this idea but would elaborate on this by allowing the recognition of such profits only where an appropriate and sufficiently reliable margin for uncertainty (risk margin) has been provided for in the liability measurement.

When the Second Liabilities Paper was released, there were two areas where the IAIS position disagreed with the preliminary conclusions of the Board.

- Participating contracts. Whereas the IAIS view is that discretionary bonuses should be accounted for as liabilities on the basis of the expected future cash flows, the Board's tentative conclusion had been that an unconditional obligation was required for future policyholder distributions to qualify as a liability. The IAIS believes that such an approach would lead to misrepresentation of the financial position and unnecessary volatility, arising essentially from the need first to record future policyholder distributions in equity and then to transfer these to liabilities once they became unconditional obligations.

However, earlier this year the Board redeliberated this issue, resulting in a tentative Board decision that constructive, as well as legal, obligations to pay policyholder dividends would give rise to a liability. This brings the IASB's position much closer to that of the IAIS.

- Credit standing. The IAIS believes that the credit standing of an insurer is not relevant to, and would be misleading in, the valuation of insurance liabilities. Despite strong opposition from its constituents the Board's unanimous, tentative conclusion is that own credit standing should be included in the valuation 
methodology. The IAIS will consider elaborating to the Board on its arguments against the use of own credit standing within liability measurement.

We observe that the IASB is also considering the inclusion of a "service margin" in addition to the current estimate and the risk margin and there seems to be some confusion about this concept that some interpret as an additional "profit margin". Before taking position on this, we would like to read more from the Board about the rational and practicalities of the "service margin". This is in fact an illustration of the need for the IASB to provide robust guidance on concepts and principles for valuation of insurance contracts so as to avoid inconsistent and inappropriate applications of the standards.

\section{Reaction to the Second Liabilities Paper}

Following its publication Rob Esson, Chair of the Insurance Contracts Subcommittee, was invited to make a presentation on the Second Liabilities Paper to the Board during an Education Session at the IASB's meeting on 22 June 2006, and subsequently at the IASB's Insurance Working Group meeting the following month. An important point made in the paper is that, if an insurance liability is measured based upon the notion of transfer, ultimate settlement with the claimant/beneficiary would be a key consideration within such a model. This message in particular attracted a great deal of support with some Board members as it reconciles the idea of valuation based upon transfer with an insurer's settlement obligations towards the policyholder.

The paper has received wide support from international organisations. Notably, CEIOPS has given public support to the paper in a letter of November 2006 to the IASB Chairman from its then Chair, Henrik Bjerre-Nielsen. The paper has also attracted much support from the insurance industry, and indeed the input received from IAIS industry observers was a valuable part of the process.

Nevertheless, it should be noted that there are certain areas of contention, as expressed by some trade associations. For example, certain sections of the industry oppose the discounting of non-life insurance liabilities.

\section{Work will Continue for Some Time to Come}

The IAIS will continue to provide further input to the IASB throughout the Phase II project, through the work of the Insurance Contracts Subcommittee as well as through its representation on the IASB's Insurance Working Group. The IASB's Discussion Paper on Phase II is expected to be released soon; and reviewing and commenting on the Discussion Paper and subsequent output and deliberations at the IASB will continue as priority work for the IAIS both over the coming months and until the direction and requirements of the Phase II standard become sufficiently clear.

In the meantime, the IAIS commented on the project led in parallel by the IASB on Fair Value Measurement. To the extent that the standard that might emerge from the fair value measurement project is possibly also applicable to insurance contracts, it is crucial that there is close communication between the two IASB projects. We observe that, in this project, Fair Value is fundamentally defined as a transfer notion (current 
exit price). However, we have some comments on this approach when it comes to liabilities, in particular those resulting from insurance contracts. To the extent that the transfer notion does not take into account ultimate settlement, then we would regard this as inappropriate for application to insurance liabilities and maybe to other liabilities.

More generally speaking, insurance supervisors as other prudential supervisors cannot ignore the impact of accounting on the overall stability of the financial system. Without opposing as such a Fair Value model, one needs to be aware of the greater difficulty to ensure the reliability and the "auditability" (and hence to consider the systemic consequences) of more extended application of the Fair Value model. This is notably the case when the measurement of Fair Value is based on inputs that are not directly extracted or straightforwardly stemming from deep and liquid markets.

IAIS work related to solvency assessment will also continue to take into account developments in international financial reporting standard setting. If general-purpose financial statements (adjusted as necessary) form the basis for insurer solvency assessment, in a principles-based environment, consistency in the implementation and application of IFRS will be a key issue. This will be particularly the case for the IFRS that results from Phase II. Due to the complexities involved and the fact that the standard is unlikely to be prescriptive - for instance, it is unlikely to specify a particular method of calculating the risk margin - there will be a need for application guidance to facilitate consistency and convergence, as well as to support the usability of IFRS as a base for solvency assessment. In this area, the joint work of the IAIS and IAA, in close liaison with the IASB and IFRIC, is important in promoting a regime where standards, guidance and required interpretations can be complementary with and support the overall IAIS objective that a single set of methodologies can be used for calculating items in both general-purpose and regulatory financial reports with as few adjustments between the two as possible. The development, implementation and application of IFRS will remain key areas for insurance supervisors for the foreseeable future.

\section{References}

IAA (2007) Measurement of Liabilities for Insurance Contracts: Current Estimates and Risk Margins, International Association of Actuaries Exposure Draft, Ottawa, February 23.

IAIS (2005a) A New Framework for Insurance Supervision: Towards a Common Structure and Common Standards for the Assessment of Insurer Solvency, Basel, IAIS (October).

IAIS (2005b) Towards a Common Structure and Common Standards for the Assessment of Insurer Solvency: Cornerstones for the Formulation of Regulatory Financial Requirements, Basel, IAIS (October).

IAIS (2005c) Issues Arising as a Result of the IASB's Insurance Contracts Project - Phase II: Initial IAIS Observations, Basel, IAIS (May).

IAIS (2006) Issues Arising as a Result of the IASB's Insurance Contracts Project - Phase II: Second Set of IAIS Observations, Basel, IAIS (May).

IAIS (2007) The IAIS Common Structure for the Assessment of Insurer Solvency, Basel, IAIS (February).

\section{About the Author}

Michel Flamée is the Vice-President of the Banking, Finance and Insurance Commission of Belgium, as well as Chair of the Executive Committee and Member of the FSF G7, Vice-Chair of the Financial Stability Committee (Belgium) and Chair of the Convergence Committee of CEIOPS. 